\title{
Analysis of the Thermal Performance of Curtain Walls in High-rise Residential Buildings
}

\author{
Sang-Tae $\mathrm{No}^{1}$ and Kang-Soo Kim* ${ }^{2}$ \\ ${ }^{1} \mathrm{Ph}$. D Student, Dept. of Architectural Engineering, Korea University, Korea \\ ${ }^{2}$ Professor, Dept. of Architectural Engineering, Korea University, Korea
}

\begin{abstract}
The curtain wall is presently being adopted widely in high-rise buildings because of its several merits in many aspects. Curtain walls, however, also have problems, such as thermal efficiency and moisture condensation, especially in countries where there are four seasons like Korea, because of wide glazing windows and metal frames that have high thermal conductivity. Furthermore, insulation efficiency is more important in high-rise buildings than in low-rise buildings when outdoor conditions worsen.

There are two main objectives in this research; first, to perform steady state conduction simulations for curtain wall materials in high-rise outdoor conditions, and second, to evaluate insulation efficiency and moisture condensation on curtain wall surfaces based on the results of the simulations.
\end{abstract}

Keywords: high-rise residential buildings; curtain walls; insulation efficiency; moisture condensation

\section{Introduction}

Construction technology has changed the form of residential structures. Furthermore, the restriction in residential areas, and the increase of building expenses have resulted in high-rise and highly dense residential buildings. Many Korean cities have highrise residential buildings along with apartments and commercial stores. Most of these residential buildings have curtain walls as exterior envelopes. Curtain walls are presently being adopted widely in highrise buildings because of their various merits. Curtain walls however, also have problems, such as thermal efficiency and moisture condensation, especially in countries like Korea, where there are four seasons, because of their wide, glazing windows and metal frames that have high thermal conductivity. Moreover, insulation efficiency is more important in high-rise buildings than in low-rise buildings when outdoor conditions worsen. The cold bridge seeps through the metal frames whose high thermal conductivity reduces energy efficiency, and during winter, interior moisture condensation causes low durability in building materials.

To avoid cold bridge and moisture condensation, mock-up thermal tests must be performed during the designing process. Mock-up tests, however, require too much labor and expense.

Some research literature focuses on the analysis

* Contact author: Kang-Soo Kim, professor, Dept. of Architectural Engineering, Korea University, 1, 5-Ka, Anamdong, Sungbuk-ku, Seoul, Korea

Tel: +82-2-3290-3335 Fax: +82-2-921-7947

E-mail: kskim@korea.ac.kr

(Received May 10, 2005; accepted August 25, 2005) of thermal performance of building. Jan Kosny et $a l .{ }^{1)}$ conducted two and three-dimensional computer simulations for several metal stud walls and their components using a finite difference computer code. Hua Ge $e t$ al. ${ }^{2}$ ) studied the effect of the thermal performance of glazing units and the frame projection on the cold draft using a large-scale metal curtain wall specimen with an environmental chamber and C.K. Cheung et al. ${ }^{3)}$ proposed energy-efficient exterior wall design strategies for high-rise apartments using some simulation tools.

A heat conduction simulation can be a very useful tool in curtain wall design because computer simulation has no limits, and requires less time and expense. Accordingly, there is a need to study the computer simulation of outdoor climate conditions with respect to high-rise buildings.

There are two main objectives in this study; first, to perform steady state conduction simulations for curtain wall materials in high-rise outdoor conditions, and second, to evaluate insulation efficiency and moisture condensation on curtain wall surfaces based on the results of the simulations.

\section{Methods}

2.1 Hypotheses regarding insulation efficiency simulations

In this study, Fluent 6 (FVM) was used as a simulation tool.

In simulating curtain walls, the following hypotheses were made to simplify calculation:

- two dimensional steady-state conditions,

- the properties of building materials do not vary with changes in temperature, 
- isotropic materials,

- the following effects are neglected:

- airflow through curtain wall frames, and

- the effects of solar and long-wave radiation on the outdoor surfaces of curtain walls.

\subsection{Heat transfer coefficients in high-rise conditions}

The heat transfer coefficient number of exterior air is very important, especially in high-rise buildings. At the external surfaces of buildings, the transfer of heat to the natural environment is a complex and variable process with respect to the height of the buildings. The work of CIBS (Chartered Institute of Building Services) gave rise to the following design rule ${ }^{4)}$ :

$$
h_{c}=4.1 V+5.8
$$

for $h_{c}$ in $\mathrm{W} / \mathrm{m}^{2} \mathrm{~K}$ and wind speed $V$ in $\mathrm{m} / \mathrm{s}$.

Wind speed varies with height because of the atmospheric boundary layer from the ground to $1 \mathrm{Km}$. Winds aloft generally have a higher velocity than the winds at ground level. In other words, at any given time or any given place, wind speed usually increases with altitude. The effect of altitude on wind speed involves two factors:

- the degree of mixing turbulent flow prevailing in the atmosphere at the given time and place as characterized by the Pasquill stability class, and

o the terrain's surface area roughness which induces surface friction at the given location.

It has generally been agreed upon that the effect of altitude on wind speed is logarithmic, and can be expressed as ${ }^{5)}$ :

$$
\frac{U_{z}}{U_{g}}=\left(\frac{H_{z}}{H_{g}}\right)^{n}
$$

where :

$U_{z}$ is the wind speed at height z (meter),

$U_{g}$ is the wind speed at ground-station height,

$H_{z}$ is the height $\mathrm{z}$,

$H_{g}$ is the ground-station height (10 meters), and

$n$ is a function of the Pasquill stability class and the terrain type

Table 1. Exponent $\mathrm{n}$ for Use in Urban Terrain

\begin{tabular}{|c|c|}
\hline Stability & Exponent $\mathrm{n}$ \\
\hline A & 0.15 \\
B & 0.15 \\
C & 0.20 \\
D & 0.25 \\
E & 0.40 \\
F & 0.60 \\
\hline
\end{tabular}

Table 1. shows various Pasquill stability types and the exponent number n. Fig.1. shows the variation of wind speed with altitude and Pasquill stability ${ }^{6}$. In this study, Pasquill stability E(exponent $n=0.4$ ) was used to simulate an adverse exterior climate condition.

The mean wind speed value at a height of $10 \mathrm{~m}$ during winter was $2.24 \mathrm{~m} / \mathrm{s}$ in Seoul. By the above equations (1) and (2), the calculated wind speed value of exterior air at a height of $400 \mathrm{~m}$ during winter was 9.8 $\mathrm{m} / \mathrm{s}$, and the heat transfer coefficient number was 45.98 $\mathrm{W} / \mathrm{m}^{2} \mathrm{~K}$. As for the interior heat transfer coefficient number, $8.29 \mathrm{~W} / \mathrm{m}^{2} \mathrm{~K}$ was adopted with ASHRAE Fundamentals. $^{7)}$

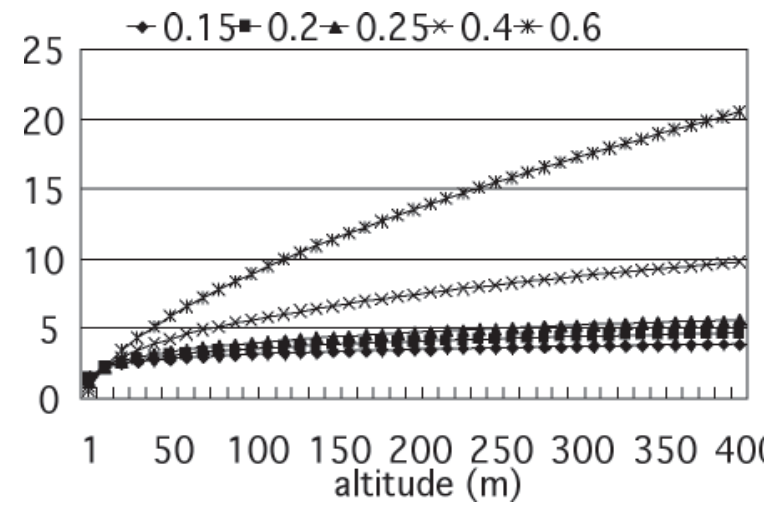

Fig.1. Uz with Various Stability and Altitude

Table 2. shows the values of the various boundary conditions used for simulation. The interior and exterior temperatures were established, considering indoor heating conditions during winter. The exterior heat transfer coefficients were established considering wind speed and building height, as shown in Fig.1.

Table 2. Boundary Conditions for Simulation with Building Height

\begin{tabular}{|c|c|c|}
\hline & Heat transfer coefficient & Temperature \\
\hline Interior & $8.29\left(\mathrm{~W} / \mathrm{m}^{2} \mathrm{~K}\right)$ & $293 \mathrm{~K}\left(20^{\circ}\right)$ \\
\hline Exterior $(10 \mathrm{~m})$ & 14.99 & \\
$100 \mathrm{~m}$ & 28.89 & \\
$200 \mathrm{~m}$ & 36.27 & $258 \mathrm{~K}\left(-15^{\circ}\right)$ \\
$300 \mathrm{~m}$ & 41.64 & \\
$400 \mathrm{~m}$ & 45.98 & \\
\hline
\end{tabular}

\subsection{Structure of curtain wall frames}

There are many types of curtain wall frames, and their shapes and materials vary. The simulation models are selected at random among the existing curtain wall frames of high- rise residential buildings constructed within the last five years.

Fig.2. shows the details of each curtain wall type. Generally, the curtain wall frame consists of a mullion (vertical frame) and a transom (horizontal frame) as well as aluminum frame, a double glazed window with an air cavity, a gasket, a sealant and a thermal break. They all have thermal breaks except type C. Type A has a double thermal break in the mullion, and the height of the building is about $170 \mathrm{~m}$. Type B has a complicated section detail in the mullion, and the height of the building is about $256 \mathrm{~m}$. Type $\mathrm{C}$ has 
no thermal breaks and a simple section detail in the mullion, but is complicated with many gaskets in the transom, and the height of the building is about $70 \mathrm{~m}$. Type D has large frames and triple glazings with argon gas, and the height of the building is about $100 \mathrm{~m}$.

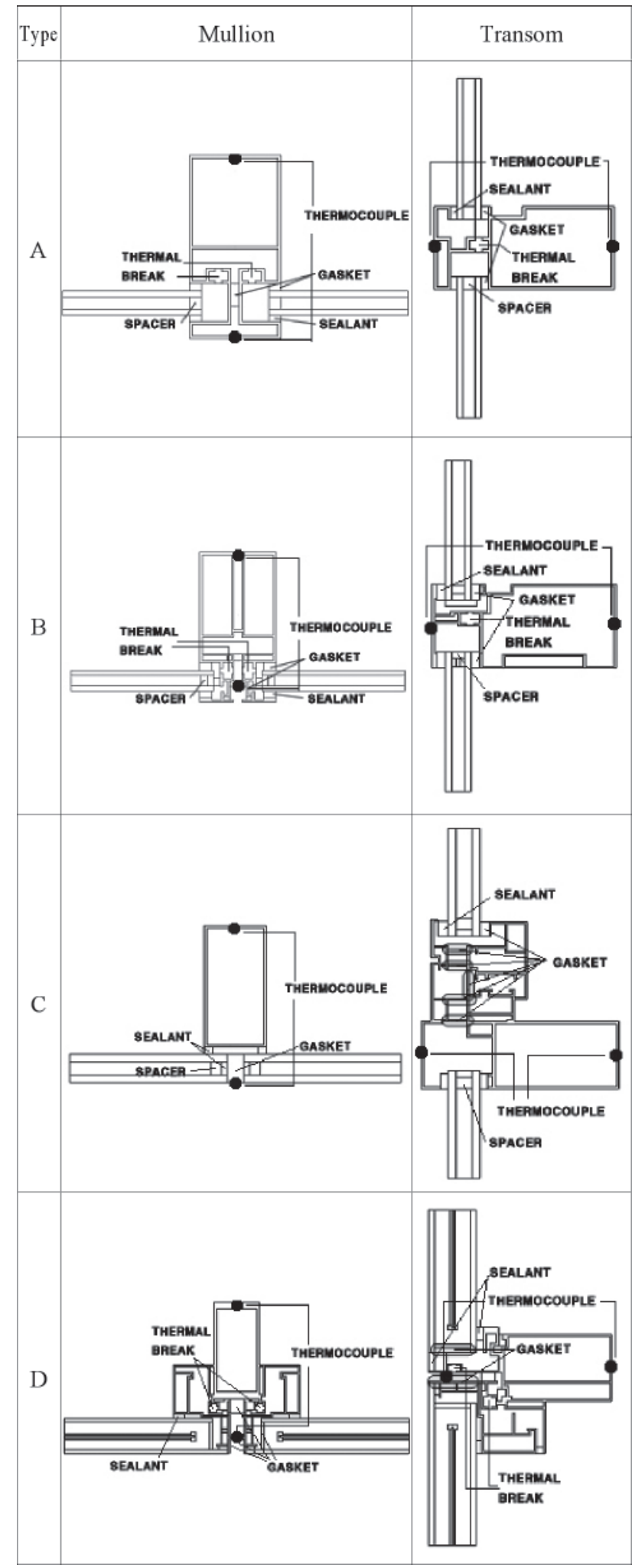

Fig.2. Mullions and Transoms for Various Curtain Wall Frames
Table 3 . shows heat conductivity in curtain wall materials. $^{8), 9)}$

Table 3. Heat Conductivity in Curtain Wall Materials

\begin{tabular}{|c|c|}
\hline Material & Heat conductivity $(\mathrm{W} / \mathrm{mK})$ \\
\hline Aluminum frame & 227.4 \\
Sealant & 0.032 \\
Spacer (aluminum) & 227.4 \\
Thermal Break & 0.03 \\
Gasket & 0.032 \\
Glass & 0.8 \\
\hline
\end{tabular}

Table 4. shows the KSF 2295 condition. KSF is the Korean Industrial Standard for engineering and construction and, KSF 2295 defines the method in testing the efficiency of condensation prevention in windows and doors. Therefore, if the interior surface temperature of the curtain wall frame is below the dew point temperature $(282.3 \mathrm{~K})$, condensation would likely occur $^{10)}$.

Table 4. Interior Temperatures and Humidity Conditions of KSF2295

\begin{tabular}{|c|c|c|c|c|}
\hline $\begin{array}{c}\text { Interior } \\
\text { temperature }\end{array}$ & $\begin{array}{c}\text { Relative } \\
\text { humidity }\end{array}$ & $\begin{array}{c}\text { Absolute } \\
\text { humidity }\end{array}$ & $\begin{array}{c}\text { Vapor } \\
\text { pressure }\end{array}$ & $\begin{array}{c}\text { Dew } \\
\text { point }\end{array}$ \\
\hline $293 \mathrm{~K}$ & $50 \%$ & $7.34 \mathrm{~g} / \mathrm{kg}$ & $8.765 \mathrm{mmHg}$ & $282.3 \mathrm{~K}$ \\
\hline
\end{tabular}

\subsection{Validation of the simulation tool}
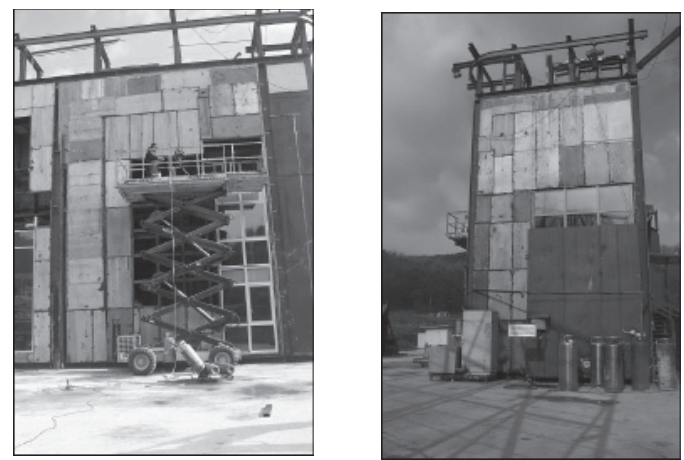

Fig.3. Curtain Wall Mock-Up Test Facility

To validate accuracy of the simulation tool, the results of simulation were compared with those of the experiment. Fig.3. depicts a curtain wall mock-up test facility based on AAMA (American Architectural Manufacturers Association) 501.5-98.

Curtain wall Type A, B, C, and D were tested in a thermal chamber with various indoor/outdoor temperatures and relative humidity cycle (total 14 cases) by the method of AAMA thermal test. Fig. 4. presents measuring temperature and condensation with thermocouples. 


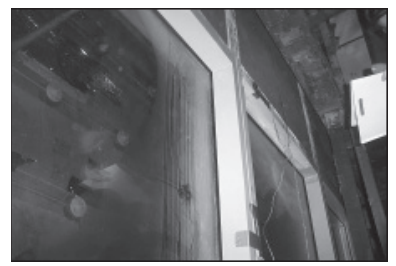

(a) Mullion

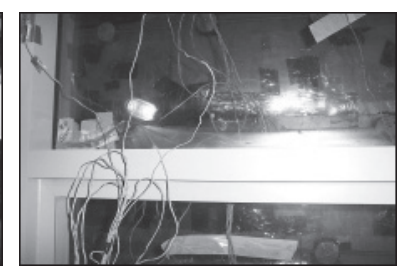

(b) Transom
Fig.4. Temperature and Condensation Measurement

Table 5. Mock-up Cold Test Conditions of 14 Cases

\begin{tabular}{|c|c|c|c|c|c|c|}
\hline \multirow{2}{*}{ Case } & \multirow{2}{*}{ Type } & \multicolumn{2}{|c|}{ Surface Temp. } & \multicolumn{2}{c|}{ Air Temp. } & \multirow{2}{*}{ RH(\%) } \\
\cline { 3 - 6 } & & In & Out & In & Out & \\
\hline 1 & A & 288 & 259.4 & 298 & 258 & 44.33 \\
2 & A & 287.3 & 258.7 & 298 & 258 & 44.33 \\
3 & B & 296 & 274.2 & 298 & 269 & 50.3 \\
4 & B & 294.4 & 271 & 298 & 269 & 50.3 \\
5 & B & 294.7 & 271.1 & 298 & 266 & 50 \\
6 & B & 294.1 & 268.4 & 298 & 266 & 50 \\
7 & B & 293.8 & 269.2 & 298 & 263 & 50 \\
8 & B & 293 & 265.9 & 298 & 263 & 50 \\
9 & B & 293 & 266.3 & 298 & 260 & 50.1 \\
10 & B & 292.2 & 262.7 & 298 & 260 & 50.1 \\
11 & C & 291.6 & 257.4 & 297 & 255 & 40.3 \\
12 & C & 291 & 258.1 & 297 & 255 & 40.3 \\
13 & D & 290.7 & 258.4 & 295 & 255 & 41.1 \\
14 & D & 289.7 & 261.3 & 295 & 255 & 41.1 \\
\hline
\end{tabular}

Table 5. shows mock-up cold test conditions of 14 cases for curtain wall type A, B, C, and D. By the AAMA test method, each curtain wall frame type was tested for 3 or 4 thermal cycles with various thermal conditions. Each cycle was tested for 2 hours. Surface Temp. shows temperature at the indoor and outdoor surfaces of curtain wall frames as shown in Fig.2. Air Temp. shows indoor and outdoor temperature of the chamber. RH shows the relative humidity ratio of the indoor chamber.

Fig.5. shows comparison of the results of the experiment and simulation. The indoor and outdoor surface temperatures of frames were compared. In indoor cases, the maximum and minimum relative errors were $0.94 \%$ and $0.08 \%$. In outdoor cases, the maximum and minimum relative errors were $2.12 \%$ and $0.25 \%$. The relative errors and temperature profile show good agreement with the experiment and simulation.

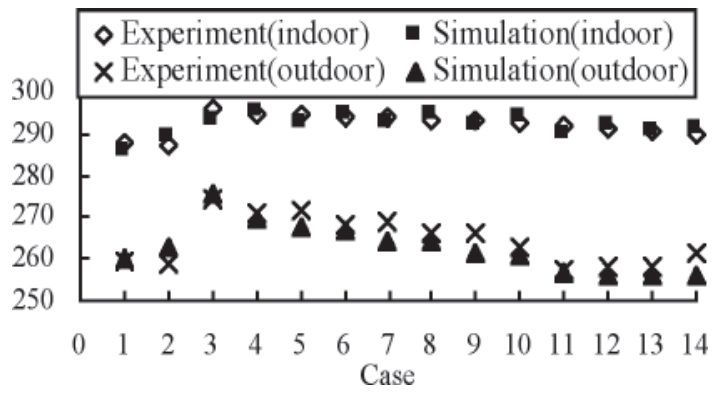

Fig.5. Results of Experiment and Simulation

\subsection{Result of the simulations}

Fig.6. shows the temperature profiles, condensation lengths, and locations of curtain walls in normal and high-rise conditions using the same curtain wall frames. Temperature profile changes at the aluminum frame were more severe than at the glazing because of high thermal conductivity. The mullion of Type A was affected by the exterior climate more than the other types were because the exterior aluminum frame penetrated the wall to the extent of inward thermal breaks. The low temperature of the exteriors was transmitted to the interiors through the aluminum frame. Type B showed more complicated section details. Both the mullion and the transom in Type B had the proper breaks designed to cut the exterior and interior aluminum frames by thermal break, gasket and sealant. Since the transom of Type C had a large aluminum frame, the transom showed more temperature changes in high-rise conditions, compared to the mullion. Because Type D also had large aluminum frames, the temperature at the aluminum frame was remarkably lower than that at the glazings, compared to the other types.

Fig.7. compares the temperature distribution in normal and high-rise conditions at the interior surface. In all the given types, the aluminum frame and the glazings showed the lowest temperatures. Except in the case of Type D, the simulation on all the types of mullions and transoms resulted in moisture condensation at the interior surface, where the lowest temperature was below the dew point temperature of $282.3 \mathrm{~K}$. The changes of temperature at the mullions were greater than at the transoms because the interior and exterior aluminum frames of the mullion were not clearly separated as in the transoms. The mullion and the transom of Type B showed less changes in the temperature of glazings and the aluminum frame compared to other types. Thus, Type B could be considered the most stable among the three types with the exception of Type D. Though Type D had a large aluminum frame, it did not result in moisture condensation. Because Type D had the triple glazings with argon gas, the joints of the frame and glazings were effectively broken thermally with gaskets, and the externally exposed frames were covered by 4 gaskets at the mullion and 2 gaskets at the transom, which played the role of thermal breaks, shutting out exterior cold temperature.

Table 6. Comparison of Condensation Lengths and Increase Ratio in Normal and High-Rise Conditions

\begin{tabular}{|c|c|c|c|c|c|c|}
\hline \multicolumn{2}{|l|}{ Type } & \multicolumn{2}{l|}{ Mullion } & \multicolumn{2}{l|}{ Transom } \\
\hline & $10 \mathrm{~m}$ & $400 \mathrm{~m}$ & $\begin{array}{c}\text { Increase } \\
\text { ratio }\end{array}$ & $10 \mathrm{~m}$ & $400 \mathrm{~m}$ & $\begin{array}{c}\text { Increase } \\
\text { ratio }\end{array}$ \\
\hline $\mathrm{A}$ & $40(\mathrm{~mm})$ & 414 & $935(\%)$ & 49 & 69 & 40.8 \\
$\mathrm{~B}$ & 40 & 56 & 40 & 9 & 13 & 44.4 \\
$\mathrm{C}$ & 8 & 36 & 350 & 31 & 50 & 61.3 \\
$\mathrm{D}$ & 0 & 0 & 0 & 0 & 0 & 0 \\
\hline
\end{tabular}




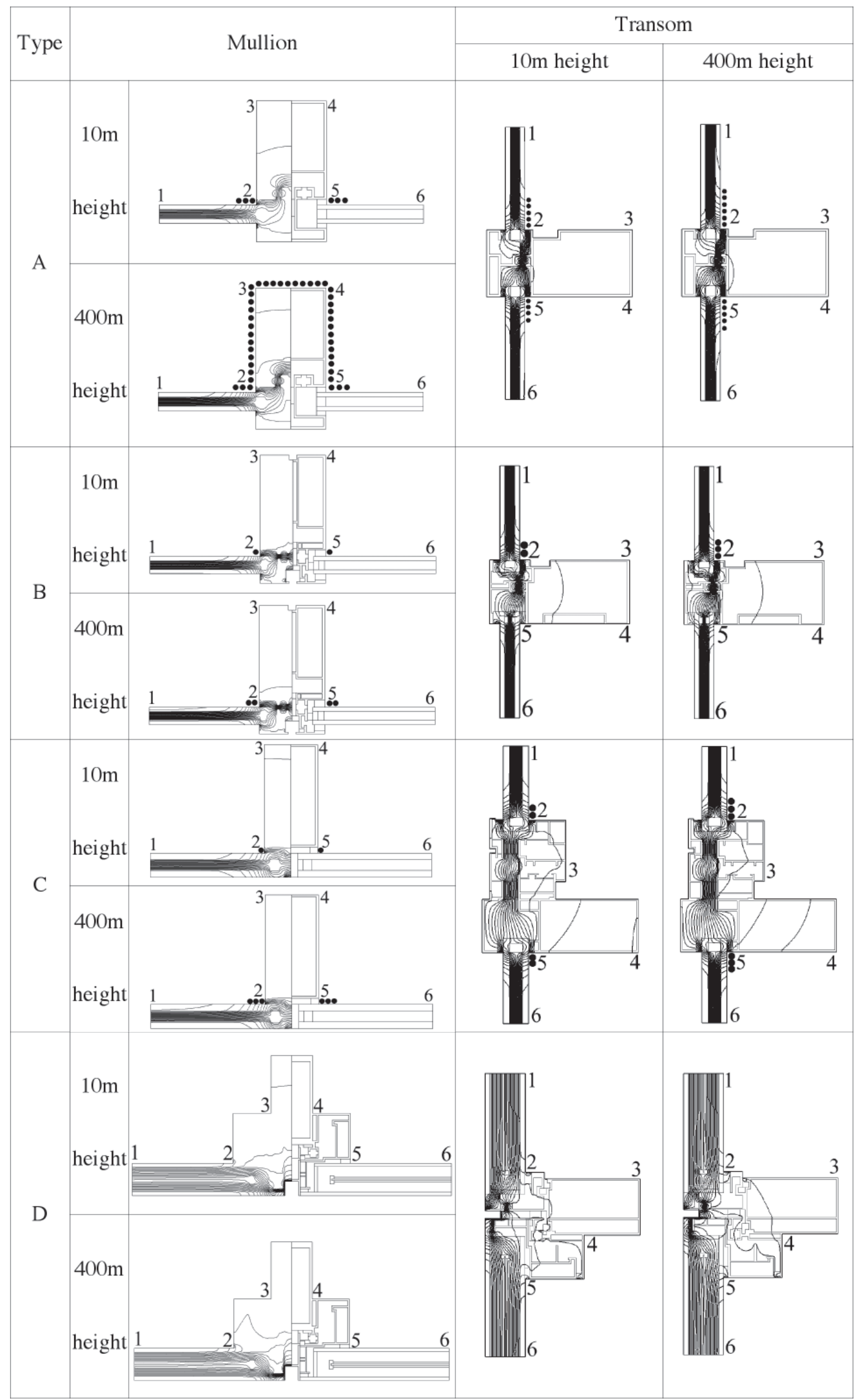

Fig.6. Temperature Profiles, Condensation Lengths, and Locations of Curtain Wall in Normal and High-Rise Conditions 

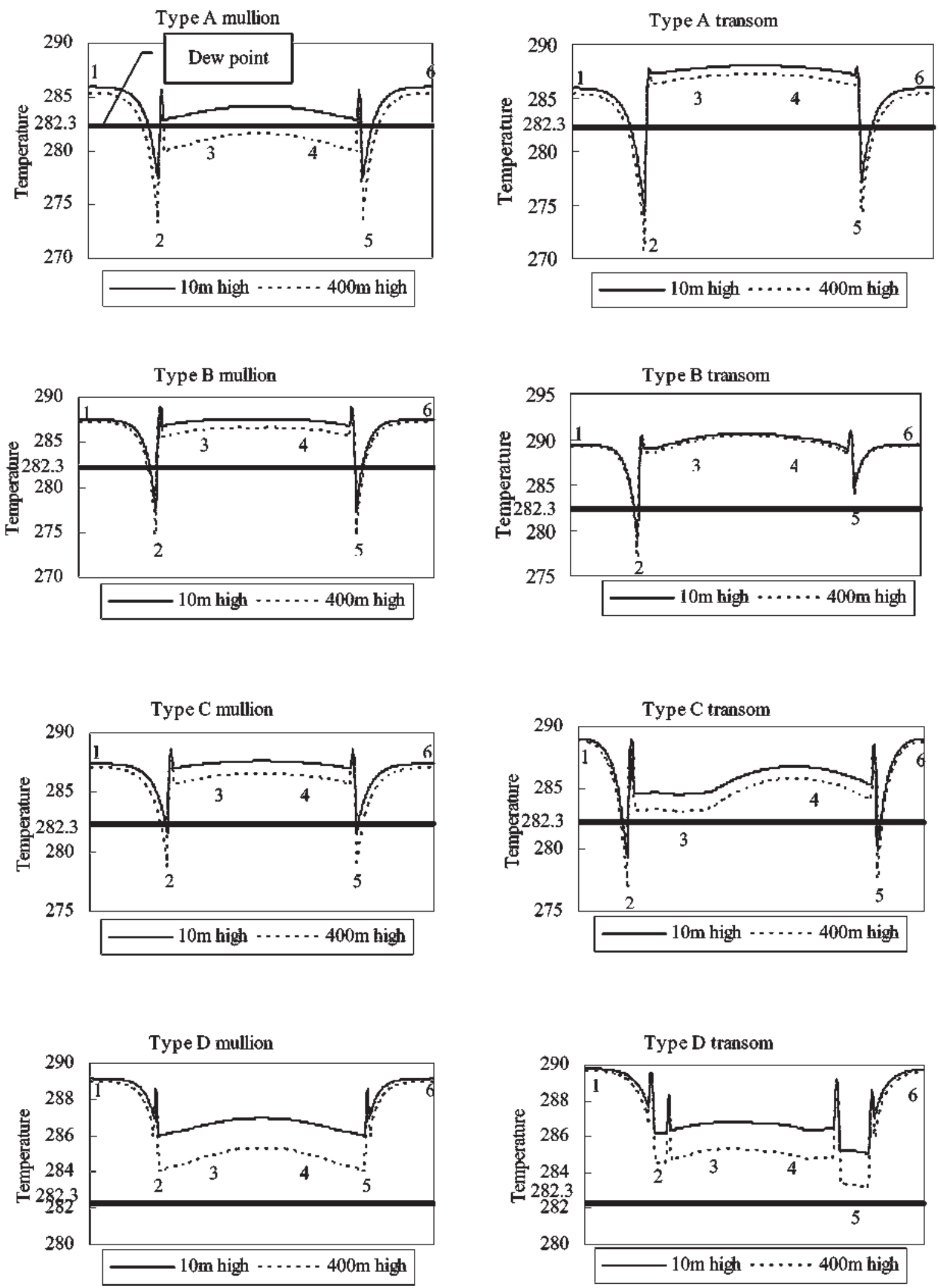

Fig.7. Comparison of Interior Surface Temperature Distribution in Normal and High-Rise Conditions 


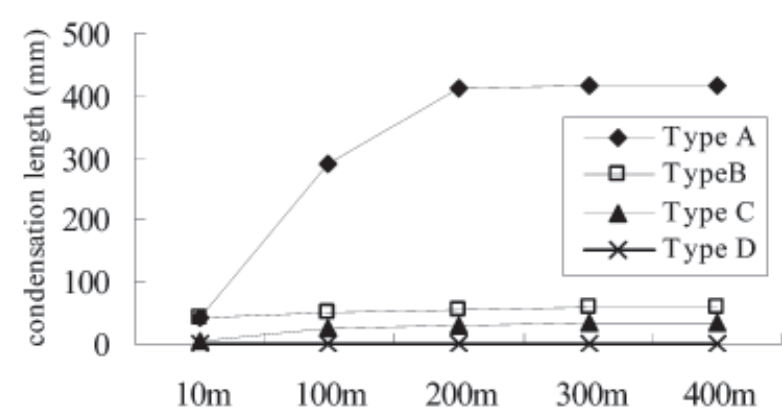

(a) Condensation length of interior Mullion surface

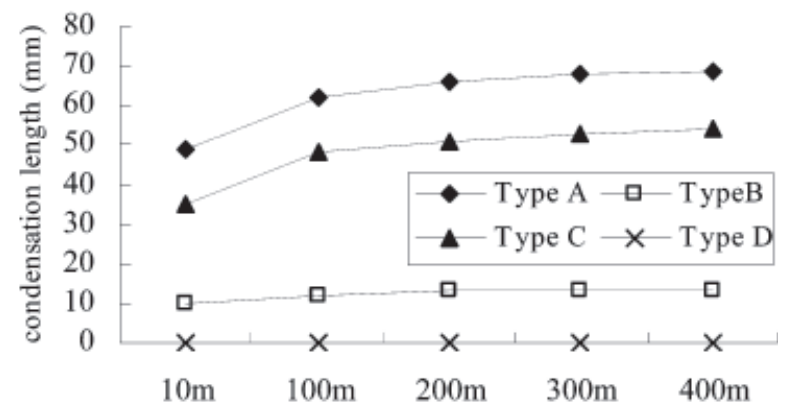

(b) Condensation length of interior Transom surface

Fig.8. Comparison of Condensation Length Increase with Building Height

To study the insulation efficiency of all types, the length of moisture condensation and its increase ratio were calculated.

Table 6. and Fig.8. show more detailed results on the increase of moisture condensation by comparing condensation lengths in normal and high-rise conditions along the interior surfaces of the curtain walls.

The simulation results of moisture condensation length showed that high-rise conditions affected the insulation efficiency of curtain walls significantly because the change in the heat transfer coefficient number by height was equal for the all types, but the increase ratio of moisture condensation length varied. The maximum increase ratio of the condensation length of mullion Type A was $935 \%$, the highest among all other types. As mentioned above, the insulation efficiency of mullion Type A was poor due to the penetrating aluminum frame. This result assumed that curtain walls with ineffective insulation would be worse in high-rise conditions. On the contrary, the condensation increase ratio of Type B was $40 \%$ (mullion), and $40.4 \%$ (transom), respectively, as Type B showed stable insulation efficiency against the changes in exterior conditions.

In all types, the higher the building is, the more condensation occurs. However, there is no significant condensation increase when building height is over 200m, as shown in Fig.8. (a) and (b).

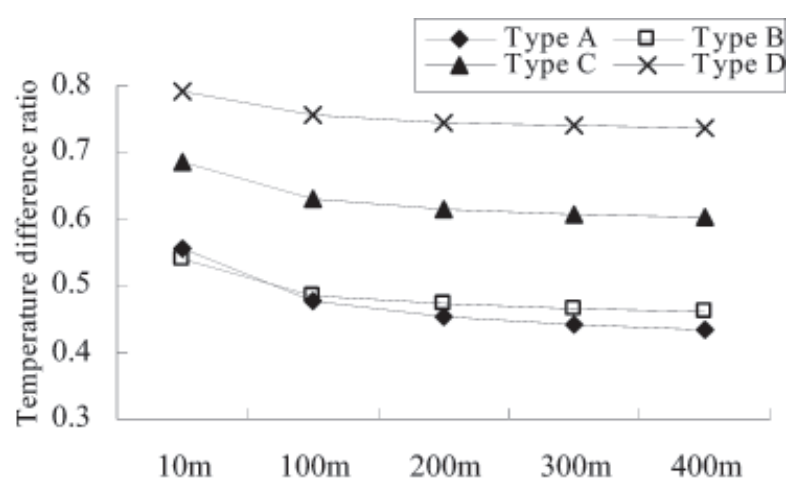

(a) $T_{D R}$ values of Mullion

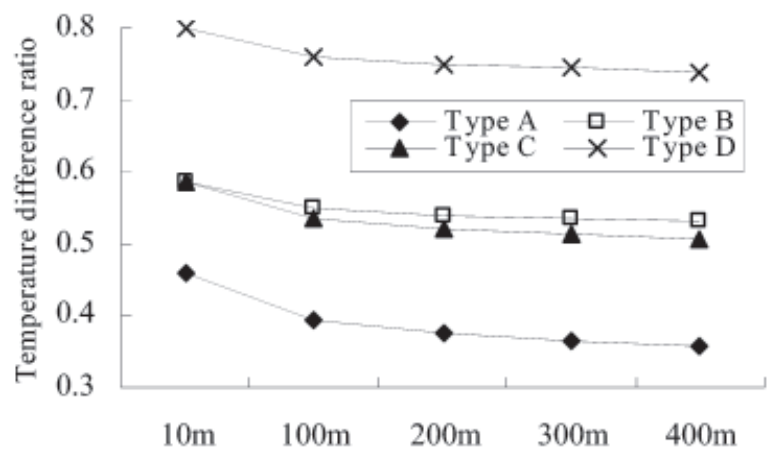

(b) $T_{D R}$ values of Transom

Fig.9. Comparison of $\mathrm{T}_{\mathrm{DR}}$ Values with Building Height

Along with the simulation method to find out the condensation length, there is another method to find out whether the condensation occurs. The TDR (temperature difference ratio) method is very useful because it needs just a one time computer simulation and uses an algebraic solution. TDR can be expressed as: ${ }^{11)}$

$$
T_{D R}=\frac{T_{l}-T_{\text {out }}}{T_{\text {in }}-T_{\text {out }}}
$$

$\mathrm{T}_{1}$ is the lowest temperature of the interior frame surface, $\mathrm{T}_{\mathrm{in}}$ is the interior air temperature,

$\mathrm{T}_{\text {out }}$ is the exterior air temperature.

$\mathrm{T}_{\mathrm{DR}}$ is a fixed value unless thermal resistance of curtain wall frame is changed. If $\mathrm{T}_{\mathrm{DR}}$ is calculated once using a simulation, $\mathrm{T}_{1}$ can be calculated algebraically by the equation (3) using arbitrary Tin and Tout. Therefore the effect of exterior condition change on $\mathrm{T}_{\mathrm{DR}}$ value was investigated. Fig.9. shows $\mathrm{T}_{\mathrm{DR}}$ values with various building height.

As is evident, $\mathrm{T}_{\mathrm{DR}}$ values in Fig.9. are not fixed because heat transfer coefficient changes according to the building height. In the high-rise condition, each $\mathrm{T}_{\mathrm{DR}}$ value must be calculated separately according to the different height. As shown in Fig.9. (a) and (b), as building becomes higher, the decrease ratio of $T_{D R}$ value becomes small. Mean decrease ratio of $T_{D R}$ value was about $1 \%$ in all mullion and transom types, when the building becomes higher from $300 \mathrm{~m}$ to $400 \mathrm{~m}$. 


\section{Conclusions}

In this study, steady state conduction simulations for curtain wall materials were performed in normal and high-rise outdoor conditions, and insulation efficiency and moisture condensation on curtain wall surfaces were evaluated according to the results of the simulations. Based on these results, the following conclusions were drawn.

- To simulate the insulation efficiency of curtain walls in high-rise conditions, this study established the heat coefficient number with the building's height.

Considering adverse conditions during winter, by the above equations (1) and (2), the calculated wind speed value of the exterior air at a height of $400 \mathrm{~m}$ was $9.8 \mathrm{~m} / \mathrm{s}$, and the heat transfer coefficient number was $45.98 \mathrm{~W} / \mathrm{m}^{2} \mathrm{~K}$.

- To validate accuracy of the simulation tool, the results of simulation were compared with those of a Mock-up test based on the AAMA method. The relative errors and temperature profile of 14 cases show good agreement with the experiment and simulation.

- The simulation results of the temperature profile for four curtain wall types showed that it is very important to separate exterior and interior aluminum frames appropriately through thermal breaks, gaskets and sealants.

In all types, the joint of aluminum frame and glazings showed the lowest temperature. The joint of the frame and glazings have an effect on the insulation efficiency of the curtain walls. Though Type D had a large aluminum frame, it showed the best insulation efficiency, as it showed no moisture condensation in normal and high-rise conditions. Because Type D had the triple glazings with argon gas, the joints of the frame and glazings were effectively broken thermally with gaskets, and externally exposed frames were covered by 4 gaskets at the mullion and 2 gaskets at the transom, which played the role of thermal breaks.

- The simulation results with regard to moisture condensation lengths showed that high-rise conditions affected the insulation efficiency of curtain walls because the change in the heat transfer coefficient number by height was equal for all types, but the increase ratio of moisture condensation length varied.

- The curtain wall with ineffective insulation would worsen in high-rise conditions. The increase ratio of the condensation length of mullion Type A was $935 \%$, the highest value among all the types. The insulation efficiency of mullion Type A was poor because of the penetrating aluminum frame. On the contrary, the condensation increase ratio of Type B was 40\% (mullion), and 40.4\% (transom), respectively as Type B showed stable insulation efficiency against changes in exterior conditions.

- In all types, the higher the building is, the higher the level of condensation. However, there is no significant condensation increase when the building height is over $200 \mathrm{~m}$. In high-rise conditions, each $\mathrm{T}_{\mathrm{DR}}$ value must be calculated separately according to height.

\section{Acknowledgments}

This research (03R\&D C04-01) was financially supported by the Ministry of Construction \& Transportation of South Korea and Korea Institute of Construction and Transportation Technology Evaluation and Planning, and the authors are grateful to the authorities for their support.

\section{References}

1) Jan Kosny, Jeffrey E. Christian. (1995) Thermal Evaluation of several configurations of insulation and structural materials for some metal stud walls, Energy and Buildings, Vol. 22, pp.157-163

2) Hua Ge, Paul Fazio. (2004) Experimental investigation of cold draft induced by two different types of glazing panels in metal curtain walls, Building and Environment, Vol. 39, pp.115-125

3) C.K. Cheung, R.J. Fuller, M.B. Luther. (2005) Energy-efficient envelope design for high-rise apartments, Energy and Buildings, Vol. 37, pp.37-48

4) Chartered Institute of Building Services (CIBS). (1979) Guide Book A, CIBS, London, Section A3

5) Wind Engineering Research Institute. (2002) Knowledge of Building Wind, pp.22-27

6) Pasquill, F. (1961) The Estimation of the dispersion of windborne material, Meteorological Magazine, 90, pp.33-49

7) American Society of Heating, Refrigerating and Air-Conditioning Engineers, Inc. (1993) ASHRAE HANDBOOK, 22.1

8) American Society of Heating, Refrigerating and Air-Conditioning Engineers, Inc. (1993) ASHRAE HANDBOOK, 36.3

9) Kwang-Woo Kim, et al. (2004) A Study on the Prevention of Surface Condensation on Lightweight Curtain Wall Structure, Proceeding of AIK, Vol.24 No.1

10) Kang-Soo Kim, Sang-Tae No. (2001) Evaluation of Insulation Efficiency in a Steel House Exterior Corner By 2D Thermal Conductivity Analysis, Journal of the AIK, Vol.17 No.5

11) Susan, R. and M. Hancock edited. (1992) Energy efficient building: A design guide, Halsted press, p. 181 